\title{
ANALISIS RISIKO KESELAMATAN DAN KESEHATAN KERJA (K3) PADA PROSES PRODUKSI LEAF SPRING DIVISI HEATING DENGAN MENGGUNAKAN METODE HIRARC DI PT. X
}

\author{
Firman Hadi Setiawan $^{(1)}$, Said Salim Dahda ${ }^{(2)}$, M. Zainnudin Fathoni ${ }^{(3)}$ \\ Program Studi Teknik Industri, Universitas Muhammadiyah Gresik \\ Email : firmanhadisetiawan25@gmail.com
}

\begin{abstract}
ABSTRAK
PT. X merupakan perusahaan manufaktur yang bergerak dalam bidang pembuatan leaf spring dan coil spring automotive. Spring merupakan komponen penting untuk menunjang kenyamanan pengendara sepeda motor maupun mobil. Pada proses pembuatan leaf spring terbagi atas tiga divisi proses produksi yaitu proses shearing, heating, dan assembling.

Penelitian ini menganalisis risiko menggunakan metode hazard identification risk assasment and risk control (HIRARC). Dari hasil identifikasi bahaya, risiko pada bahaya yang teridentifikasi akan dilakukan penilaian severity dan likelihood untuk menentukan risk level. Dari penilaian risiko yang telah dilakukan, potensi bahaya diklasifikasikan menjadi 3 level yaitu low risk, moderate risk, dan high risk. Hasil penelitian menunjukan pada proses heating furnace terdapat potensi bahaya yang paling dominan yaitu dengan level moderate risk dengan nilai risiko 6 material panas dan walking beam. Hasil pada proses press quenching terdapat potensi bahaya yang berpengaruh dengan kategori level high risk dengan nilai risiko 16 yaitu kabel terkelupas. Dan hasil pada proses tempering furnace terdapat potensi bahaya yang paling berpengaruh dengan kategori level high risk dengan nilai risiko 16 yaitu conveyor tempering. Pengendalian risiko menggunakan acuan OHSAS 18001.
\end{abstract}

Kata Kunci : K3, HIRARC, Penilaian risiko, Pengendalian risiko. 


\section{PENDAHULUAN}

PT. X merupakan perusahaan manufaktur yang bergerak dalam bidang pembuatan leaf spring dan coil spring automotive. Spring merupakan komponen penting untuk menunjang kenyamanan pengendara sepeda motor maupun mobil. Pada proses pembuatan leaf spring terbagi atas tiga divisi proses produksi yaitu proses shearing, heating, dan assembling. Dimana proses pemotongan dan pembentukan awal spring dilakukan di divisi proses produksi shearing. Setelah itu dilakukan proses pemanasan awal untuk pembentukan lengkungan dan pemansan akhir untuk membentuk karakteristik leaf di divisi heating. Proses selanjutnya adalah kegiatan pengecatan dan finishing di divisi assembling. Pada divisi heating departemen produksi leaf spring PT. X masih ditemukan beberapa kasus kecelakaan kerja yang berbahaya. Perusahaan ini sudah menetapkan SOP yang ditetapkan oleh divisi K3 pada proses produksi seperti kelengkapan APD dan memakai APD sesuai area kerja. Namun perusahaan ini masih belum memiliki program khusus yang ditetapkan guna mengantisipasi dan mengurangi kecelakaan kerja pada departemen produksi, sehingga program minimal yang dilakukan adalah melakukan breefing rutin kepada semua karyawan tentang keselamatan dan kesehatan kerja.

Peran dan kinerja sumber daya manusia dalam perusahaan tidak lepas dari adanya bahaya kecelakaan kerja. Banyak faktor yang mempengaruhi adanya kecelakaan kerja, seperti faktor cara kerja yang salah, lingkungan kerja yang tidak aman, peralatan kerja yang kurang maksimal alat peindung diri yang kurang memadai, human eror, dan faktor-faktor lainnya. Dampak dari kecelakaan kerja juga bermacam-macam, mulai dari kecelakaan ringan seperti tersandung, terpeleset dan kecelakaan besar seperti kebakaran atau kecelakaan yang mengakibatkan kematian. Setelah dilakukan wawancara dengan kepala bagian divisi heating bahwa masih terdapat adanya kecelakaan kerja. Dilihat bahwa kecelakaan kerja yang terjadi di PT. X sebanyak 25 kejadian pada tahun 2018. Dampak dari adanya kecelakaan kerja yang mengakibatkan karyawan mengalami sakit/cidera sehingga tidak bisa bekerja dalam kurun waktu tertentu juga mengakibatkan perusahaan tidak dapat menyelesaikan pekerjaan dengan kurun waktu tertentu sehingga perusahaan mengalami kerugian dalam hal itu.

Permasalahan yang teridentifikasi selanjutnya adalah kondisi K3 pada proses produksi saat ini masih banyak ditemui kondisi lingkungan kerja yang kurang aman mulai dari penataan material yang kurang aman, kurangnya kepedulian pekerja dalam pemakaian APD (alat pelindung diri), kondisi pengaman mesin yang tidak memadai hal seperti itu dapat membahayakan dan merugikan pekerja dan perusahaan karena didalam UU No. 1 tahun 1970 yang berisi hak tenaga kerja serta syarat-syarat keselamatan yang wajib dipenuhi oleh perusahaan, dan undangundang tentang K3 lainnya.

Dengan masih adanya kecelakaan kerja yang mengalami luka berat merupakan indikasi bahwa penerapan program K3 masih perlu diperbaiki, maka dalam penelitian ini akan dibahas tentang bagaimana tindakan-tindakan yang harus dilakukan oleh perusahaan dalam mengidentifikasi, menilai, dan melakukan pengendalian risiko berupa rekomendasi perbaikan program $\mathrm{K} 3$ untuk mencegah dan mengurangi tingkat kecelakaan kerja pada PT. X dengan pendekatan Hazard Identification Risk Assesment and Risk Control (HIRARC).

\section{TINJAUAN PUSTAKA}

\section{$H A Z A R D$}

hazard (bahaya) adalah sifat dari suatu bahan, cara kerja suatu alat, cara melakukan suatu pekerjaan, tempat dan posisi atau kondisi kerja lingkungan kerja, yang 
menimbulkan kerusakan atau kerugian manusia, harta benda, penyakit akibat kerja, cedera, cacat sementara maupun permanen, dan kematian. Bahaya adalah segala sesuatu termasuk situasi atau tindakan yang berpotensi untuk menimbulkan kecelakaan atau cidera pada manusia, kerusakan atau gangguan lainnya

\section{KESELAMATAN DAN KESEHATAN KERJA (K3)}

Keselamatan dan Kesehatan Kerja harus dikelola sebagaiamana dengan aspek lainnya dalam perusahaan seperti operasi, produksi, listrik, sumber daya manusia. Keselamatan dan kesehatan kerja adalah suatu kondisi kerja yang terbebas oleh dari risiko kecelakaan yang dapat mengakibatkan cidera, penyakit, kerusakan serta gangguan lingkungan. Kondisi tersebut hak dari pekerja harus dipehatikan oleh setiap perusahaan. Keselamatan dan kesehatan kerja merupakan ketentuan perundangan dan memiliki landansan hokum yang wajib dipatuhi semua pihak, baik pekerja, pengusaha atau pihak terkait lainnya.

\section{KONSEP HIRARC}

Hazard Identification Risk Assesment and Risk Control (HIRARC) adalah salah satu persyaratan dalam penerapan SMK3 berdasarkan OHSAS 18001:2007. Pada klausul 4.3.1 OHSAS 18001:2007 organisasi harus menetapkan prosedur mengenai identifikasi bahaya (Hazard Identification), penilaian risiko (Risk Assesment), dan menentukan pengendaliannya (Risk Control). Keseluruhan dari proses ini juga disebut sebagai manajemen risiko (Ramli, 2010:79). Menurut Rachmawati (2017:329) proses pembuatan HIRARC dibagai menjadi 4 langkah yaitu :

a. Mengklasifikasikan jenis pekerjaan

b. Mengidentifikasi jenis bahaya

c. Melakukan penilaian risiko (menganalisa dan menghitung kemungkinan terjadinya bahaya serta tingkata keparahannya)

d. Menentukan apakah risiko dapat ditoleransi dan mengimplementasikan pengukuran tingkat bahaya jika diperlukan

Untuk memudahkan dalam memahami konsep HIRARC dapat dilihat flowchart dari proses HIRARC pada gambar berikut.

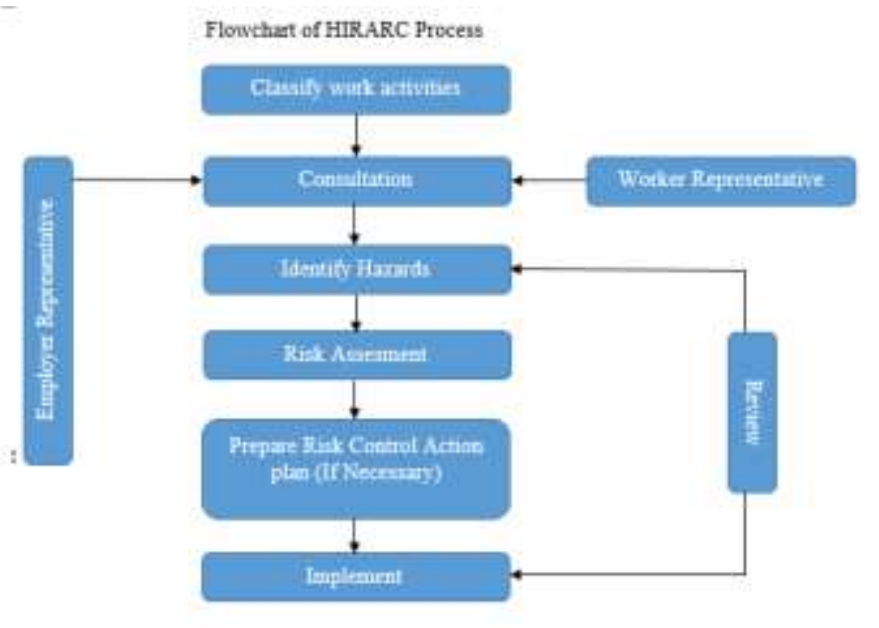

Gambar 2.5 Flowchart Proses HIRARC

Sumber. Degortument of Occupartomal Safery and Healsh Mailoyia (2008-7)

1. Klasifikasi kegiatan kerja

Pada tahap ini dilakukan pengklasifikasikan aktivitas kerja dengan tingkat kemiripan pekerjaan setiap wilayah geografis atau fisik didalam atau diluar lokasi pekerjaan, tahapan dalam proses produksi atau layanan, dan lain-lain.

2. Konsultasi kegiatan kerja

Pada tahap ini dilakukan konsultasi dengan pemilik perusahaan dan para pekerja untuk menentukan solusi terbaik dari berbagai risiko yang terdapat dalam lingkungan kerja.

3. Identifikasi bahaya

Tujuan identifikasi bahaya adalah untuk mengamati lingkungan kerja atau aktivitas kerja yang memiliki potensi bahaya yang ada di lingkungan kerja. Identifikasi bahaya merupakan langkah awal dalam manajemen risiko yang 
Vol. 1, No. 4, 2020

menjadi landasan dalam pencegahan kecelakaan atau pengendalian risiko. Metode yang sesuai untuk mengidentifikasi bahaya adalah dengan cara proaktif yaitu mencari bahaya sebelum keadaan yang tidak diinginkan terjadi yang menimbulkan dampak atau akibat yang merugikan (Ramli, 2010).

Salah satu teknik identifikasi bahaya yang bersifat proaktif dengan menggunakan brainstorming yaitu dengan cara melakukan pertemuan kelompok untuk membahas kondisi tempat kerja. Setiap amggota kelompok dapat mengemukakan pendapat atau temuannya mengenai bahaya yang ada pada lingkungan kerja. Teknik ini bermanfaat untuk mengidentifikasi dan menganalisa dalam setiap langkah pekerjaannya sehingga dapat dilakukan pencegahan yang tepat dan efektif (Ramli, 2010).

4. Penilaian risiko

Penilaian risiko dilakukan melalui dua tahap proses, yaitu analisa risiko dan evaluasi risiko.

a. Analisa risiko dilakukan dimaksudkan untuk menentukan besarnya suatu risiko yang merupakan kombinasi antara kemungkinan terjadinya dan keparahan bila risiko tersebut itu terjadi menunjukan seberapa mungkin kecelakaan itu terjadi, menurut standar Depertament of Occupational Safety and Health Malaysia (2008) severity atau likelihood diberi rentang antara suatu risiko yang jarang sampai dengan risiko yang dapat terjadi setiap saat. Skala likelihood dan severity dapat dilihat pada tabel berikut

\begin{tabular}{|c|c|c|}
\hline Rating & Eikelithood & Brample \\
\hline 5 & Most Likely & The most liked rerult of the harad devent realition \\
\hline 4 & Possible & Hats a good chance of occurring and it nof thintwal \\
\hline 3 & Concebable & Maght be occur at sometane in fincre \\
\hline 2 & Remote & Has nor been known to occhir qferr many years \\
\hline$t$ & Inxoncetvable & Is practlcally impossible and hes never occurred \\
\hline
\end{tabular}

Tabel Skala "Severity" pada standar Depertament of Occupational Safety and Health Malaysia

\begin{tabular}{|c|c|l|}
\hline Rating & Severity & \multicolumn{1}{|c|}{ Example } \\
\hline 5 & Catastrophic & $\begin{array}{l}\text { Numerous fatalities, irrecoverable property } \\
\text { damage and productivity }\end{array}$ \\
\hline 4 & Fatal & $\begin{array}{l}\text { Approximately one single fatality major } \\
\text { property damage if hazard is realized }\end{array}$ \\
\hline 3 & Serious & Non-fatal injury, permanent disability \\
\hline 2 & Minor & Disabling but not permanent injury \\
\hline 1 & Negligible & $\begin{array}{l}\text { Minor abrasions, bruises, cuts, first aid type } \\
\text { injury }\end{array}$ \\
\hline \multicolumn{2}{|c|}{ Sumber: Depertament of Occupational Safety and Health Malaysia } \\
(2008)
\end{tabular}

Setelah didapatkan nilai likelihood dan severity selanjutnya menetukan nilai risiko untuk mendapatkan level risiko. Untuk mendapatkan nilai risiko dihitung dengan menggunakan rumus sebagai berikut :

$$
\text { Risk = likelihood } \mathrm{x} \text { severity }
$$

5. Pengendalian risiko

Pengendalian risiko merupakan langkah penting dan menentukan dalam keseluruhan manajemen risiko. Risiko yang telah diketahui besar dan potensi akibatnya harus dikelola dengan tepat, efektif dan sesuai dengan kemampuan dan kondisi perusahaan. OHSAS 18001 memberikan pedoman hirarki pengendalian risiko yang terdiri dari lima pengendalian untuk bahaya K3 yaitu eliminasi, subtitusi, engginering control, administrative control, dan alat pelindung diri (Ramli, 2010:104).

a. Eliminasi

Eliminasi adalah teknik pengendalian dengan menghilangkan sumber bahaya. Teknik ini sangat efektif 
karena sumber daya di eliminasi sehingga potensi risiko bisa di hilangkan. Teknik ini menjadi pilihan pertama dalam hirarki pengendalian risiko.

\section{b. Subtitusi}

Subtitusi adalah teknik pengendalian bahaya dengan cara mengganti bahan, alat atau cara kerja dengan yang lain yang lebih aman atau rendah bahayanya sehingga kemungkinan kecelakaan dapat ditekan.

c. Pengendalian teknis

Pengendalian teknis adalah pengendalian yang di lakukan dengan memperbaiki atau menambah suatu sarana atau peralatan teknis, seperti penambahan peralatan, perbaikan pada desain komponen, mesin dan material.

d. Pengendalian administratif

Pengendalian administratif adalah sebuah pengendalian risiko dengan membuat suatu peraturan, peringatan rambu, prosedur, instruksi kerja yang lebih aman atau pemeriksaan kesehatan.

e. Penggunaan alat pelindung diri

Dalam konsep K3, penggunaan alat pelindung diri merupakan pilihan terakhir dalam pencegahan kecelakaan karena penggunaan alat pelindung diri bukan untuk mencegah adanya kecelakaan tetapi hanya untuk mengurangi efek atau keparahan kecelakaan.

\section{Implementasi}

Dalam tahap ini dilakukan tindakan perbaikan dalam proses kerja perusahaan mengenai pengendalian risiko (jika diperlukan) antara pemegang penuh kekuasaan dan para pekerja dalam proses produksi. Dalam melakukan tahap implementasi pihak perusahaan harus melakukan dengan konsisten agar tercapai tujuan dalam pengendalian risiko.

\section{METODOLOGI PENELITIAN}

Penelitian ini dilakukan dengan cara melakukan perizinan ke perusahaan PT. X untuk survey secara langsung pada kondisi perusahaan. Sehingga pada study pendahuluan ini akan ditemui kondisi aktual perusahaan. pada tahap awal ini hal yang dilakukan ialah melakukan wawancara kepada pengambil keputusan/responden untuk dijadikan acuan dalam melakukan identifikasi permasalahan sebagai langkah awal penyelesaian masalah. Data untuk penelitian ini didapatkan dari urutan proses produksi divisi heating dimulai dari heat treatment (heating furnace), press quenching, tempering furnace. Selain itu untuk data yang dikumpulkan dari penelitian ini adalah aktivitas pekerjaan yang memiliki potensi bahaya pada proses produksi divisi heating di PT. X.

\section{IDENTIFIKASI BAHAYA}

Tahap identikasi bahaya ini dilakukan dengan metode brainstorming dengan penyebaran kuisioner dengan pihak expert atau berpengalaman pada bidangnya yaitu mengidentifikasi bahaya dan risiko terhadap lingkungan kerja, peralatan kerja, dan mesin yang berhubungan dengan prosedur kerja. Data didapatkan dari kuisioner terhadap pekerja divisi heating yang sudah memahami pada bidang pekerjaannya sehingga mempermudah melakukan analisis terhadap potensi bahaya dan risiko terjadinya kecelakaan.

\section{PENILAIAN RISIKO}

Penilaian risiko didapatkan dengan pendekatan risk management yaitu dengan menentukan nilai risk score dengan cara mengalikan likelihood dengan severity terhadap risiko dari bahaya yang sudah teridentifikasi. Pengisian nilai likelihood dan severity diperoleh dengan cara penyebaran kuisioner kepada pekerja yang expert pada bidangnya. Setelah menentukan nilai risiko selanjutnya membuat peta risiko untuk melihat level 
Vol. 1, No. 4, 2020

risiko berdasarakan nilai Risk Score yang sudah didapatkan. Pemetaan nilai risiko dilakukan dengan cara menentukan hasil nilai risiko sesuai standar Depertament of Occupational Safety and Health Malaysia (2008) yaitu nilai 1-4 adalah low risk (risiko ringan) risiko dapat diterima, pengendalian tambahan tidak diperlukan, nilai 5-12 adalah moderate risk (risiko sedang) memerlukan pendekatan yang direncanakan untuk mengendalikan bahaya dan berlaku tindakan sementara jika diperlukan, nilai 15-25 high risk (risiko tinggi) Kegiatan tidak boleh dilaksanakan atau dilanjutkan sampai risiko telah direduksi. Jika tidak memungkinkan mereduksi risiko, maka penanganan harus segera dilakukan. Adapun penentuan level risiko dilihat pada tabel berikut

\begin{tabular}{|c|c|c|c|c|c|c|c|}
\hline \multirow{2}{*}{ No } & \multirow{2}{*}{ Lokani/Altintar } & \multirow{2}{*}{$\begin{array}{l}\text { Sunter } \\
\text { Pestyetboh }\end{array}$} & \multirow{2}{*}{ Bathys } & \multirow{2}{*}{ Rinibo } & \multicolumn{3}{|c|}{ Penilais Rinka } \\
\hline & & & & & $\mathrm{t}$ & 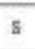 & $\begin{array}{l}\text { Gevel } \\
\text { Baile }\end{array}$ \\
\hline \multirow{4}{*}{1} & \multirow{4}{*}{ 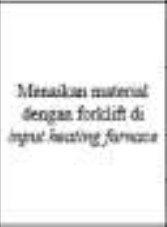 } & Foallit & $\begin{array}{c}\text { Tertidea } \\
\mathbf{1}\end{array}$ & $\begin{array}{l}\text { Luak } \\
\text { menar, }\end{array}$ & 2 & 2 & 1 \\
\hline & & Meuternal & $\begin{array}{l}\text { Matenal } \\
\text { jutubi } \\
\text { bili }\end{array}$ & tiak & 2 & 2 & I \\
\hline & & Matmial pase & $\begin{array}{c}\text { Temben } \\
\text { lolit }\end{array}$ & Luka bàม & 3 & 2 & M \\
\hline & & Asp & Tertinop & \begin{tabular}{|l|} 
Gomproun \\
pemafuna
\end{tabular} & 2 & 1 & t \\
\hline \multirow{8}{*}{2} & \multirow{8}{*}{$\begin{array}{l}\text { byou tratenal be } \\
\text { hiotive fornace }\end{array}$} & Mental & $\begin{array}{l}\text { Jatiblibe } \\
\text { kinising } \\
\text { coes }\end{array}$ & $\begin{array}{l}\text { Lolz pata } \\
\text { talne }\end{array}$ & 2 & 2 & t \\
\hline & & Waikng boon & \begin{tabular}{|l|} 
Topm \\
tarepet
\end{tabular} & $\begin{array}{c}\text { Loba poris } \\
\text { talay }\end{array}$ & 2 & 3 & M \\
\hline & & 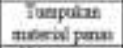 & $\begin{array}{c}\text { Teritenas } \\
\text { keliti }\end{array}$ & Luta baker & 2 & 2 & I \\
\hline & & 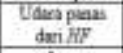 & $\begin{array}{l}\text { Telweril } \\
\text { badin }\end{array}$ & 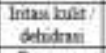 & 2 & 1 & 1 \\
\hline & & $\begin{array}{c}\text { Xap } \\
\text { serclong }\end{array}$ & Telhirap & $\begin{array}{l}\text { Ginagues } \\
\text { pemifosen }\end{array}$ & 2 & $t$ & I \\
\hline & & $\begin{array}{c}\text { Sempitus diflos } \\
\text { oggan }\end{array}$ & Tertury & $\begin{array}{l}\text { Cangruin } \\
\text { penafune }\end{array}$ & 2 & 1 & $\mathrm{t}$ \\
\hline & & Paner $N F$ & Intelor & troa biker & 2 & 2 & I \\
\hline & & Ietenan oli & $\begin{array}{c}\text { Terpeles } \\
\text { et }\end{array}$ & wata & 2 & $t$ & I \\
\hline \multirow{15}{*}{3} & \multirow{15}{*}{ Aress puevekty } & Manrial peas & $\begin{array}{c}\text { Tedkena } \\
\text { nùt }\end{array}$ & Lalstedx & 3 & 2 & M \\
\hline & & $\begin{array}{c}\text { Serpitan } \\
\text { lopase peas }\end{array}$ & $\begin{array}{c}\text { Terkens } \\
\text { zút }\end{array}$ & Labiablex & 2 & 2 & 1 \\
\hline & & $\begin{array}{c}\text { Percikn oli } \\
\text { Prana }\end{array}$ & $\begin{array}{c}\text { Terbena } \\
\text { hliti }\end{array}$ & Inla bular & 2 & $t$ & I \\
\hline & & $\begin{array}{c}\text { Asap } \\
\text { quonckys }\end{array}$ & $\begin{array}{c}\text { Pemiafa } \\
\text { a }\end{array}$ & $\begin{array}{l}\text { Gutgens } \\
\text { pernfouan }\end{array}$ & 2 & 1 & I \\
\hline & & Aol estregar & Tenjept & 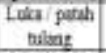 & 2 & 3 & M \\
\hline & & $\begin{array}{l}\text { Connoer } \\
\text { gumelong }\end{array}$ & $\begin{array}{c}\text { Tejejpit: } \\
\text { teppint } \\
t\end{array}$ & $\begin{array}{c}\text { Lulas bovar } \\
\text { prish } \\
\text { tulang }\end{array}$ & 3 & 2 & M \\
\hline & & $\begin{array}{c}\text { Kasel } \\
\text { veloliugas }\end{array}$ & $\begin{array}{c}\text { Kesetri } \\
\mathrm{m}\end{array}$ & $\begin{array}{l}\text { Lula bikar } \\
\text { imenitenal }\end{array}$ & 4 & 4 & H \\
\hline & & Plan HF & $\begin{array}{l}\text { Terikena } \\
\text { baden }\end{array}$ & \begin{tabular}{c|} 
Irtasi filit \\
detidass
\end{tabular} & 2 & t & $t$ \\
\hline & & Fandelt nocoor & Terjęi & $\begin{array}{c}\text { Itika/ prath } \\
\text { milay }\end{array}$ & 2 & 3 & M \\
\hline & & Detu lozan & $\begin{array}{l}\text { Polun } \\
\text { atura }\end{array}$ & \begin{tabular}{l|} 
Gratrian \\
pentuan
\end{tabular} & 2 & 1 & 1 \\
\hline & & Bak pescing & Teterbu: & Lasober & 3 & 2 & $M$ \\
\hline & & $D_{k}$ & Tenge & Lua & 2 & 3 & $M$ \\
\hline & & Detas & $\begin{array}{l}\text { Poluen } \\
\text { utana }\end{array}$ & $\begin{array}{l}\text { Ourctian } \\
\text { peruthasa }\end{array}$ & 2 & 1 & $I$ \\
\hline & & Cr grewhing & Tetolis $x$ & Ludoter & 3 & 2 & M \\
\hline & & Tetein eh & $\begin{array}{c}\text { Terpeles } \\
\text { ef }\end{array}$ & Lubs & 3 & 2 & M \\
\hline 4 & 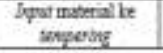 & Manerial pras & $\begin{array}{c}\text { Teribens } \\
\text { milt }\end{array}$ & Latho boles & 4 & 2 & M \\
\hline
\end{tabular}

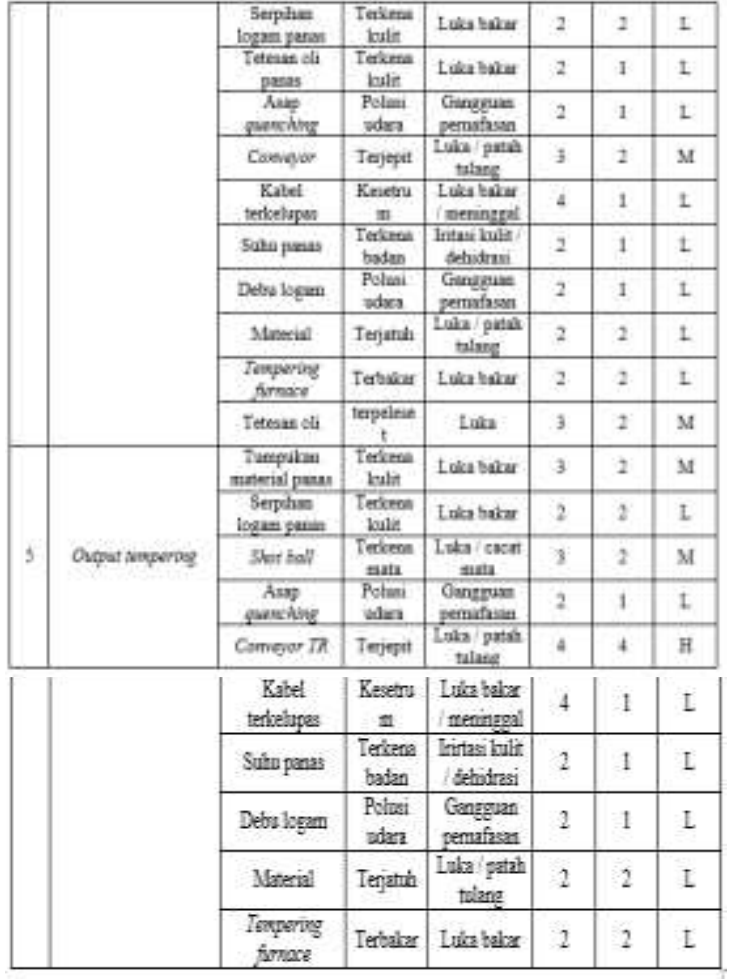

Setelah dilakukan penentual level risiko, selanjtunya adalah pengendalian risiko yang dilakukan dengan brainstorming dengan kepala bagian divisi heating pengendalian risiko difokuskan pada risiko yang memiliki level moderate risk (risiko sedang) dan high risk (risiko tinggi) karena pada level low risk (risiko rendah) tidak memerlukan pengendalian risiko.

\section{PENGENDALIAN RISIKO}

Pengendalian risiko dilakukan untuk dilakukan untuk mengeliminasi dan mencegah risiko agar tidak menimbulkan kecelakaan kerja pada proses produksi divisi heating serta mempertimbangkan semua alternatif atau solusinya sesuai dengan kondisi perusahaan. Kontrol risiko dibagi menjadi beberapa kategori yaitu eliminasi, subtitusi, pengendalian teknis, pengendalian administratif, pengendalian alat pelindung diri. Pengendalian risiko dapat dijelaskan pada tabel berikut. 


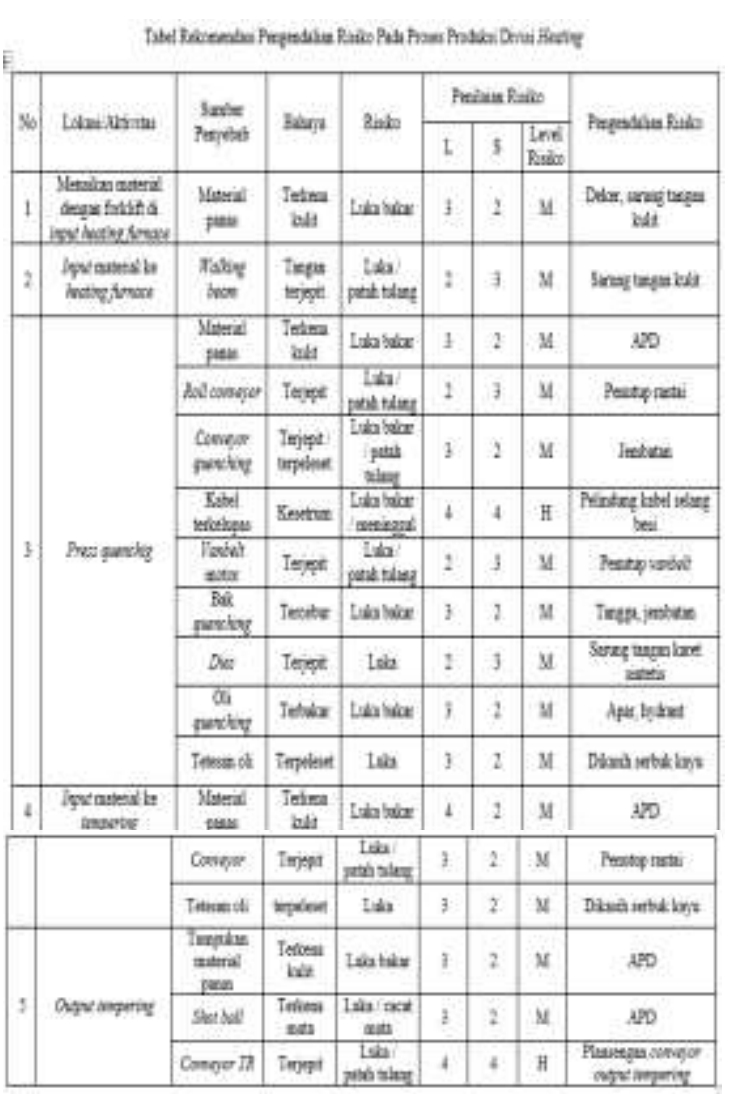

\section{HASIL DAN PEMBAHASAN}

Nilai risiko pada proses heating furnace terdapat dua belas sumber penyebab terjadi bahaya. Terdapat sepuluh sumber potensi bahaya yang memiliki level low risk (risiko rendah) yang tidak memerlukan pengendalian risiko, dan terdapat dua sumber potensi bahaya yang memiliki level moderate risk (risiko sedang) yang memerlukan tidakan pengendalian risiko

Nilai risiko pada proses press quenching terdapat lima belas sumber penyebab terjadinya bahaya. Enam sumber potensi bahaya yang memiliki level low risk (risiko rendah) yang tidak memerlukan pengendalian risiko, terdapat delapan sumber potensi bahaya yang memiliki level moderate risk (risiko sedang) yang memerlukan pengendalian risiko dan satu sumber potensi bahaya yang memiliki level high risk (risiko tinggi) yang memerlukan tidakan pengendalian risiko.

Nilai risiko pada proses tempering furnace terdapat dau puluh satu sumber penyebab terjadinya bahaya. Lima belas sumber potensi bahaya yang memiliki level low risk (risiko rendah) yang tidak memerlukan pengendalian risiko, terdapat lima sumber potensi bahaya yang memiliki level moderate risk (risiko sedang) yang memerlukan pengendalian risiko dan satu sumber potensi bahaya yang memiliki level high risk (risiko tinggi) yang memerlukan tidakan pengendalian risiko.

\section{KESIMPULAN}

Dari hasil yang telah didapatkan dari penelitian ini dengan metode Hazard Identification Risk Assesment and Risk Control di PT. X maka dapat diambil kesimpulan sebagai berikut :

1. Potensi bahaya yang terjadi pada proses produksi heating berdasarkan tabel 4.4 dapat diidentifikasi sebagai berikut :

a. Pada proses heating furnace terdapat dua belas langkah pekerjaan yang memiliki potensi bahaya dan dua langkah pekerjaan memiliki potensi bahaya yang paling dominan yaitu material panas dengan nilai 6 dan walking beam dengan nilai 6 .

b. Pada proses press quenching terdapat lima belas langkah pekerjaan yang memiliki potensi bahaya dan satu langkah pekerjaan memiliki potensi bahaya yang paling berpengaruh yaitu kabel terkelupas dengan nilai 16.

c. Pada proses tempering furnace terdapat dua puluh satu langkah pekerjaan yang memiliki potensi bahaya dan satu langkah pekerjaan memiliki potensi bahaya yang paling berpengaruh yaitu conveyor TR dengan nilai 16.

2. Hasil penilaian risiko pada proses produksi heating berdasarkan tabel 4.5 adalah sebagai berikut :

a. Pada dua belas potensi bahaya pada proses heating furnace, terdapat dua bahaya memiliki kategori level moderate risk sumber penyebabnya yaitu material panas, walking beam dan sepuluh bahaya kategori low risk 
sumber penyebabnya yaitu forklift, material, asap, tumpukan material panas, udara panas $H F$, asap quenching, serpihan/debu logam, burner $H F$, tetesan oli.

b. Pada lima belas potensi bahaya pada proses press quenching terdapat delapan bahaya memiliki kategori level moderate risk sumber penyebabnya yaitu roll coveyor, material panas, conveyor quenching, vanbelt motor, bak quenching, dies, oli quenching, tetesan oli, enam bahaya memiliki kategori level low risk sumber penyebabnya yaitu serpihan logam panas, percikan oli panas, asap quenching, panas $\mathrm{HF}$, debu logam, debu, dan satu bahaya memiliki level high risk sumber penyebabnya yaitu kabel terkelupas.

c. Pada dua puluh satu potensi bahaya pada proses tempering furnace terdapat lima bahaya memiliki kategori moderate risk sumber penyebabnya yaitu material panas, conveyor, tetesan oli, tumpukan material panas, shot ball, lima belas bahaya memiliki kategori low risk sumber penyebabnya yaitu serpihan logam panas, tetesan oli panas, asap quenching, kabel terkelupas, suhu panas, debu logam, material, tempering furnace, dan satu bahaya memiliki kategori high risk sumber penyebabnya yaitu conveyor $T R$.

3. Hasil rekomendasi pengendalian risiko pada proses produksi heating berdasarkan Tabel 4.7 adalah sebagai berikut :

a. Pengendalian risiko pada proses heating furnace adalah sebagai berikut :

- Bahaya pekerja saat forklift menaikan material ke input heating furnace sumber penyebab bahaya pada material panas yang terkena kulit. Pengendalian risiko yang dapat dilakukan adalah pengendalian administratif dengan cara memakai deker kulit yang anti panas, dan memakai sarung tangan kulit.

- Bahaya pekerja saat input material ke heating furnace sumber penyebab bahaya pada walking beam yang mengakibatkan terjepit. Pengendalian risiko yang dapat dilakukan adalah pengendalian teknik dengan cara perbaikan desain agar tidak ada celah yang berpotensi terjepit dan pengendalian risiko administratif dengan cara menggunakan sarung tangan kulit.

b. Pengendalian risiko pada proses press quenching adalah sebagai berikut :

Bahaya kerja yang memiliki level high risk pada proses quenching sumber penyebabnya adalah kabel terkelupas yang mengakibatkan luka bakar/meninggal akibat tersengat listrik. Pengendalian risiko ini yang dapat dilakukan adalah pengendalian subtitusi dengan cara mengganti bahan pelindung kabeh dengan pelindung selang besi yang anti bakar agar kabel tidak mudah terkelupas.

c. Pengendalian risiko pada proses tempering furnace adalah sebagai berikut :

Bahaya pekerja yang memiliki level high risk pada saat output tempering sumber penyebabnya adalah conveyor pada output tempering yang dapat mengakibatkan terjepit. Pengendalian risiko yang dapat dilakukan adalah pengendalian teknik dengan cara menambah plengsengan pada rantai conveyor output tempering. 


\section{DAFTAR PUSTAKA}

Anizar. 2009. Teknik Keselamatan dan Kesehatan Kerja. Yogyakarta. Graha Ilmu.

AS/NZS 4360. 2004. Risk Management Guidelines. Sydney. Standards Australia International Ltd.

. Departement of Occupational Safety and Health Ministry of Human Resources. 2008. Guedelines for Hazard Identification, Risk Assesment and Risk Control. Malaysia. JKKP DP 127/789/4-47 ISBN 978-983-2014-621.

Go, A, A, G., Liem, Y, B. 2015. Perbaikan Keselamatan dan Kesehatan Kerja Dengan Metode HIRARC di PT. Ruberrindo Jaya. Jurnal Tirta, Vol. 3, No. 2, pp. 421-426.

Halim, L, N., Togar, W, S, P., 2016. Perancangan Dokumen Hazard Identification Risk Assesment Risk Control (HIRARC) Pada Perusahaan Furniture. Jurnal Tirta, Vol. 4, No. 2, pp. 279-284.

Irawan, S., Panjaitan, T, W, S., Bendatu, L, Y., 2015. Penyusunan Hazard Identification Risk Assesment and Risk Control (HIRARC) di PT.X. Jurnal Tirta, Vol. 3, No. 1, pp. 15-18.

Rachmawati, P., 2017. Kesehatan Keselamatan Kerja Pada UKM Industri Batik Tulis Tangan Dengan Pendekatan HIRARC Studi Kasus Batik Tulis Giriloyo. Jurnal riset multidisiplin untuk menunjang pengembangan industry nasional

Ramli, S., 2010. Sistem Management Keselamatan \& Kesehatan Kerja OHSAS 18001. Jakarta. PT. Dian Rakyat.

Santoso, G., 2004. Manajemen Keselamatan \& Kesehatan Kerja. Jakarta. Prestasi Pustaka Publisher.
Supriyadi, Nalhadi, A., Rizaal, A., 2015. Identifikasi Bahaya dan Penilaian Risiko K3 Pada Tindakan Perawatan \& Perbaikan Menggunakan Metode HIRARC Pada PT.X. Jurnal SENASSET.

Wijaya, A., Togar, W, S, P., Herry, C, P. 2015. Evaluasi Kesehatan dan Keselamatan Kerja Dengan Metode HIRARC Pada PT. Charoen Pokphand Indonesia. Jurnal Tirta, Vol. 5, No. 1, pp. 29-34.

Hidayat, H., Jufriyanto, M., \& Rizqi, A. (2021). Perancangan RCM (Reliability Centered Maintenance) Untuk Mengurangi Downtime Mesin Pembuat Botol (Studi Kasus PT IGLAS (Persero), Gresik). MATRIK : Jurnal Manajemen Dan Teknik Industri Produksi, 21(2), 157 - 164. doi:10.30587/matrik.v21i2.2038

Hidayat, H. (2020). Application of the EOQ (Economic Order Quantity) Method in Determining Chemical Supplies in PT. Semen Indonesia. International Journal of Science, Engineering and Information Technology, 5(1), 226230 .

Hidayat, Jufriyanto, M., Wasiur, A., \& Ningtyas, A. H. P. (2020). Analysis Of Load Variations On ST 60 Steel Using Vickers Method. International Journal of Science, Engineering and Information Technology, 05(02), 5-9. https://doi.org/10.21107/ijseit.v5i1.89 40 